\title{
UNDERSTOREY INFLUENCE ON LEAFROLLER POPULATIONS IN HAWKE'S BAY ORGANIC APPLE ORCHARDS
}

\author{
D.J. ROGERS ${ }^{1}$, J.T.S. WALKER ${ }^{1}$, I.C. MOEN ${ }^{1}$, F. WEIBEL ${ }^{2}$, \\ P.L. LO ${ }^{1}$ and L.M. COLE ${ }^{1}$ \\ ${ }^{1}$ HortResearch, Private Bag 1401, Havelock North, New Zealand \\ ${ }^{2}$ Research Institute of Organic Agriculture (FiBL), CH-5070, Switzerland \\ Corresponding author: drogers@hortresearch.co.nz
}

\begin{abstract}
Leafrollers (Tortricidae) were collected from apple foliage and understorey vegetation in six commercial organic apple orchards in Hawke's Bay over one season. Assessments were made of plant species present in the understorey at the time of collection. All leafroller larvae were reared to adults on artificial diet to identify leafroller species and parasitoids. Nearly half $(47 \%)$ of all leafrollers collected in these orchards were located in the understorey, highlighting the importance of understorey and its management for the control of leafroller. Dock, clover and dandeliontype plants contributed $25 \%$ to the overall understorey, yet hosted $75 \%$ of the leafrollers collected from the understorey. Dolichogenidea sp. was the most abundant parasitoid (79\%) attacking leafrollers found amongst the apple foliage, whereas Glyptapanteles demeter was dominant in the understorey (61\%). Generally the number of leafrollers in an orchard was proportional to the abundance of broadleaf weeds and inversely proportional to parasitism.
\end{abstract}

Keywords: leafroller, Tortricidae, parasitism, understorey, apple.

\section{INTRODUCTION}

Although several species of leafrollers are pests of commercial horticulture in New Zealand, the lightbrown apple moth (LBAM, Epiphyas postvittana Walker) is the key species affecting Hawke's Bay apple orchards (Lo et al. 2000). It originated from Australia and is found throughout New Zealand. Parasitoids and predators occurring in orchards undoubtedly have an impact on leafroller populations thereby contributing to leafroller control. The level of leafroller infestation and damage in some organic apple orchards in Hawke's Bay is very high, but infestation can be minor in other orchards despite similar management programmes. While the absence of broad-spectrum insecticide applications in organic orchards probably increases beneficial insect activity and the diversity of species involved with biological control, other factors influence leafroller populations in orchards. Little is known about the complex interrelationships between leafroller infestation and parasitism or predation. This is complicated further by the different habitats for pests and natural enemies present in the understorey of orchards and the main fruit tree host.

The abundance of leafroller parasitoids has been studied previously in Hawke's Bay, on a range of plants near orchards where pest management was based on broad-spectrum insecticides (Suckling et al. 1998). That study reported highest parasitism by the larval parasitoid Dolichogenidea sp. on shelter or scrub weeds, and lower rates on understorey plant species. A complex of Dolichogenidea species constitute the most widespread and abundant leafroller parasitoid in New Zealand.

The aim of this research was to determine whether understorey plant species composition influenced the observed differences in leafroller populations between organic 
orchards. The abundance and species of leafrollers and their parasitoids was determined for both the understorey and apple foliage. Sward management that may reduce leafroller populations within organic apple orchards is discussed.

\section{METHODS}

Leafroller larvae were collected from six commercial organic apple orchards, of which four were located on the Heretaunga Plains of Hawke's Bay and two were in Central Hawke's Bay (approximately $50 \mathrm{~km}$ further south and at a higher altitude). Separate 90-minute searches were carried out on apple foliage and understorey plants at each orchard. Any vegetation that was suspected of harbouring larvae (webbed or rolled leaves, feeding damage or frass) was removed for later examination in the laboratory. Understorey searches focussed on known host plants and broadleaf species directly under the tree (the former herbicide strip, not in the mown alleyways) that was typically rank growth. Orchards were selected that were known to have low, medium or high leafroller populations based on research from a long-term study of the factors regulating leafroller populations. The searches were conducted in late January and early February 2002 (referred to as 'summer'), and April and early May (referred to as 'autumn'). The number of leafroller larvae, pupae and parasitoid cocoons was recorded. Larvae and pupae were reared through to adulthood in the laboratory at $20^{\circ} \mathrm{C}$ on artificial diet (Singh 1983) to enable identification of leafroller species and parasitoids. Percent parasitism was defined as (number of parasitoids emerged/(total leafrollers - dead larvae)) x 100. Assessments of the plant species present in the understorey of each orchard were carried out on the same day as the initial leafroller search. A $1.8 \mathrm{~m}$ x $1.3 \mathrm{~m}$ frame was placed on the ground under trees and the percentage ground cover of each plant species within that frame was estimated. This was repeated between five and ten times depending on the uniformity of the understorey, at different positions within the localised leafroller search area on each orchard. Dandelion-type plants included dandelion (Taraxacum officinale), hawksbeard (Crepis capillaris), hawkbit (Leontodon taraxacoides) and catsear (Hypochoeris radicata). ANOVA (Minitab release 12.1) was used on angular transformed percentage parasitism data, otherwise means and SEMs (standard error of the mean) were used.

\section{RESULTS AND DISCUSSION}

Most of the larvae (72\%) successfully reared to adulthood were identified as LBAM (Table 1). This was similar to the proportion found by Charles et al. (1996) in larval collections from canefruit in Hastings. However, Suckling et al. (1998) found the brownheaded leafroller (BHLR, Ctenopseutis obliquana) to be the most abundant larvae (41\%) followed by LBAM $(16 \%)$ on host plants adjacent to insecticide treated apple orchards. Our study was conducted in organic orchards with resident leafroller populations where the dominant host plant was apple. On apple leaves and fruit, Lo et al. (2000) found $94.3 \%$ and $95.7 \%$ of the leafrollers were LBAM in Hawke's Bay and Nelson respectively over three years. Greenheaded leafroller (GHLR, Planotortrix octo) on an orchard near Twyford (orchard A), and a higher proportion of BHLR in Central Hawke's Bay (Orchards E and F; Table 1), contributed to the comparatively lower percentage of LBAM in our study. The conclusion that LBAM is the dominant species in Hawke's Bay apple orchard environs is based on unparasitised larvae only as we did not determine the species of parasitised larvae. However, it is probably reasonable to extrapolate this species composition from the unparasitised larvae subset to the whole leafroller population by assuming that the parasitoids were not selective between species. There is some evidence to support this assumption in respect to parasitism of leafrollers by Dolichogenidea sp. on mature apple trees (Suckling et al. 2001). 
TABLE 1: The number of leafroller larvae reared to adults and identified (from both the understorey and apple foliage), and the percentage of LBAM from each orchard.

\begin{tabular}{cccccc}
\hline Orchard & LBAM & GHLR & BHLR & Other & \%LBAM \\
\hline A & 19 & 23 & 9 & 1 & 37 \\
B & 21 & 0 & 3 & 0 & 88 \\
C & 2 & 0 & 0 & 1 & nd $^{1}$ \\
D & 37 & 0 & 1 & 1 & 95 \\
E & 108 & 1 & 18 & 2 & 84 \\
F & 34 & 3 & 14 & 7 & 59 \\
Total & 221 & 27 & 45 & 12 & $72(10.8)$ \\
Mean (SEM) & & & & &
\end{tabular}

${ }^{1}$ Too few leafroller larvae to meaningfully calculate.

Although a total of 798 leafroller larvae was found from all samples, only 305 were reared to adults with the remainder either parasitised or dying. The number of leafroller larvae collected from individual orchards was highly variable and ranged from 15-325 (Table 2). Overall, more than twice as many leafroller larvae were found during timed searches in autumn compared with summer (Table 2). This is consistent with previous larval collections and pheromone trap catches in New Zealand (Lo et al. 2000; Thomas \& Burnip 1993). All of the orchards in our study showed this increase with the exception of orchard A. This orchard also had a higher proportion of GHLR, but it is not obvious how this could have influenced the result. Orchards B and E had the highest percentage increase in leafrollers from summer to autumn and also the highest percentage of leafrollers in the understorey during autumn (orchard $\mathrm{C}$ was excluded due to low numbers of leafroller larvae). This suggests understorey host plants may provide a habitat that can lead to large increases in orchard leafroller populations. Nearly half (47\%, mean of the six orchards) of all leafroller larvae collected from these orchards were located in the understorey, highlighting the importance of understorey plants as alternative leafroller hosts in apple orchards.

TABLE 2: The percentage of leafroller larvae (LR) found in the understorey (US) in summer and autumn during a 90-minute search, and the percentage increase from summer to autumn. $N$ is the total number of leafroller larvae collected in both apple foliage and the understorey.

\begin{tabular}{|c|c|c|c|c|c|}
\hline \multirow[b]{2}{*}{ Orchard } & \multicolumn{2}{|c|}{ Summer } & \multicolumn{2}{|c|}{ Autumn } & \multirow{2}{*}{$\begin{array}{l}\% \text { LR } \\
\text { increase }\end{array}$} \\
\hline & $\mathrm{N}$ & $\%$ LR in US & $\mathrm{N}$ & $\%$ LR in US & \\
\hline A & 83 & 36.1 & 54 & 40.7 & -35 \\
\hline B & 16 & 25.0 & 73 & 57.5 & 356 \\
\hline C & 3 & $\mathrm{nd}^{1}$ & 12 & 66.7 & 300 \\
\hline D & 29 & 24.1 & 72 & 13.9 & 148 \\
\hline $\mathrm{E}$ & 32 & 40.6 & 293 & 74.1 & 815 \\
\hline F & 47 & 46.8 & 84 & 29.8 & 79 \\
\hline Total & 210 & & 588 & & 180 \\
\hline Mean (SEM) & & $34.5(4.4)$ & & 47.1(9.4) & \\
\hline
\end{tabular}

${ }^{1}$ Too few leafroller larvae to accurately calculate.

The primary leafroller host plants (dock, clover and dandelion-type) comprised $25 \%$ $(\mathrm{SEM}=8.2)$ by area of understorey, but hosted $75 \%(\mathrm{SEM}=7.1)$ of all leafroller larvae found. Timed searches for leafroller larvae during 2001 on these same organic orchards 
have also highlighted the importance of broadleaf weeds, such as dock, as leafroller hosts (Walker et al. 2002). The composition of the understorey and the understorey plants supporting leafroller larvae are shown in Figure 1. Although grasses and bare ground were the two highest categories that made up the understorey ground cover, no leafroller larvae were found in these.

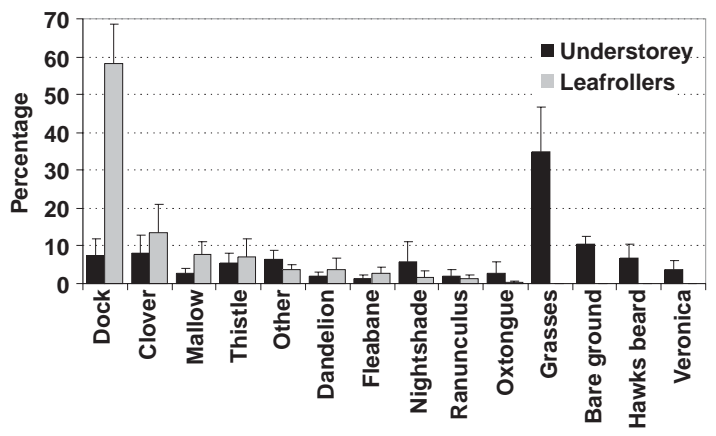

FIGURE 1: The mean ground cover $(\%)$ of the plant species found in the understorey of six organic orchards, and the percentage of leafrollers found on each of those plants.

Dolichogenidea sp. was the most common larval parasitoid $(57.5 \%$ of those parasitised), followed by G. demeter (33\%), across the 6 properties (Table 3 ). However, when apple foliage and understorey data were separated, G. demeter was the dominant parasitoid collected from leafrollers in the understorey. Parasitism by Dolichogenidea sp. was significantly higher in apple foliage compared with understorey $(\mathrm{P}<0.01)$. The reverse was seen for $G$. demeter $(\mathrm{P}<0.01)$ with higher rates of parasitism in the understorey. The association of G. demeter with low growing host plants, such as white clover, is consistent with previous parasitism studies (Suckling et al. 1998, 2001; Walker et al. 2002).

TABLE 3: The mean parasitoid species composition (\%) on apple foliage and understorey plants. Values are the total for summer and autumn. $\mathrm{N}$ is the number of parasitoids, while the figure in parentheses is the SEM.

\begin{tabular}{lrrrrrr}
\hline & \multicolumn{2}{c}{ Apple } & & \multicolumn{2}{c}{ Understorey } & \\
\cline { 2 - 3 } \cline { 5 - 6 } Parasitoid & & $\mathrm{N}$ & & $\mathrm{N}$ & Combined $^{1}$ \\
\hline Dolichogenidea sp. & $78.5(9.1)$ & 141 & & $29.2(5.7)$ & 29 & $57.5(11.2)$ \\
Glyptapanteles demeter & $13.6(8.4)$ & 22 & & $61.3(6.3)$ & 102 & $33.0(10.8)$ \\
Trigonospila brevifacies & & 12 & & 5 & 6.3 \\
Meteorus pulchricornis & & 3 & & 6 & 2.5 \\
Other & & 2 & & 1 & 0.8 \\
\hline
\end{tabular}

${ }^{1}$ Both apple foliage and understorey.

The overall mean parasitism rate of leafroller larvae was 48.8\% (SEM=6.2). However, determining the impact of parasitism on leafroller populations in organic orchards requires a larger more detailed study (Charles et al. 1996; Van Driesche et al. 1991). In this study higher levels of parasitism appear to be associated with lower leafroller populations within an organic orchard (Fig. 2). This relationship could be interpreted as suggesting that the parasitoids are regulating the leafroller populations. However, high levels of parasitism may simply reflect greater arthropod biodiversity in these orchards, including other species contributing to leafroller mortality. It is noteworthy that Australian 
life-table studies on LBAM (Danthanarayana 1983) concluded that predation was the key mortality factor of all life stages, excluding adults, with spiders and earwigs the most common predators. But this Australian research only reported a very low rate $(0-2 \%)$ of mortality attributable to Dolichogenidea sp., whereas in New Zealand it has been found to be significantly higher (20-50\%, Suckling et al. 1998; 35\%, Suckling et al. 2001).

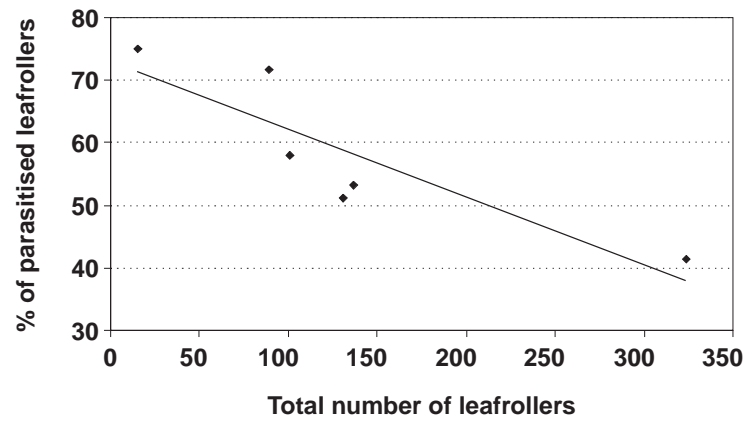

FIGURE 2: Relationship between number of leafroller larvae found and parasitism $(\%)\left(\mathbf{R}^{2}=0.76\right)$ at six organic Hawke's Bay orchards. Values are combined for understorey and apple foliage, and summer and autumn.

There was a correlation between the size of the total leafroller population within an orchard and the percent composition of leafroller host plant species (dock, clover and dandelion-type) available in the understorey (Fig. 3). This supports the concept that the abundance of alternative leafroller host plants can influence leafroller populations in organic orchards. This concept is reasonable considering the limited resources for leafroller larvae on apple trees during winter compared with the understorey. However, there are many other interacting factors that can influence leafroller populations in an organic orchard, such as immigration, pesticides, biological control and sward management. Thomas \& Burnip (1993) found sheep grazing during winter dramatically reduced the over-wintering leafroller population in one orchard. In summer, grazing or a single pass with a mower was also very effective at reducing leafrollers in that trial.

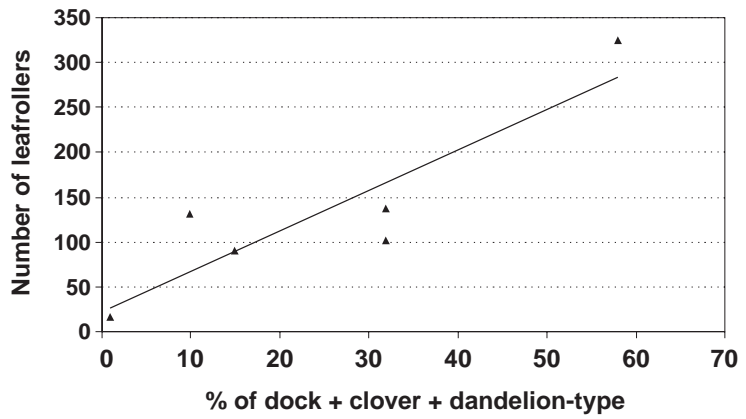

FIGURE 3: Relationship between the contribution of dock, clover and dandeliontype plants to the understorey ground cover $(\%)$ and the total number of leafroller larvae found in each orchard $\left(R^{2}=0.79\right)$. Values are combined for understorey and apple foliage, and summer and autumn, for the six orchards in the study. 


\section{CONCLUSION}

This study has clearly shown that broadleaf weeds, particularly dock, are important leafroller hosts in organic orchards in Hawke's Bay. While more extensive studies on the influence of understorey plants on leafroller populations are required, it is believed that sward management practices to control broadleaf weeds require more attention. While removal of dock could be beneficial for leafroller control, such a strategy is not suggested for white clover, which also has an important role fixing nitrogen. In a study by Burnip \& Suckling (1997), it was concluded white clover was the most suitable legume species for organic orchard understoreys, as it was already present in orchards throughout the country, and of the 11 legumes tested, it was the least favoured by leafrollers. Organic orchards in our study with low leafroller populations also had fewer broadleaf weeds and higher rates of parasitism. Many orchardists are interested in managing the understorey to enhance parasitism by providing additional floral resources for adult parasitoids. This has been investigated by Irwin et al. (1999) who found planting coriander gave significant increases in parasitism of leafroller larvae by Dolichogenidea sp. However, in organic apple orchards it may be equally important to reduce leafroller populations to lower levels through sward management. Baggen et al. (1999) refer to the concept of a 'selective food plant' that provides benefits to natural enemies but does not confer any benefits to the pest. Our study highlights the need to consider the impact of non-crop plant diversity as part of an integrated management strategy for leafrollers in orchards.

\section{ACKNOWLEDGEMENTS}

New Zealand Pipfruit Ltd, the MAF Sustainable Farming Fund and the Foundation for Research, Science Technology provided funding for this work. Thanks to Graham Burnip, Jill McLaren and Philippa Stevens whose comments greatly improved this paper.

\section{REFERENCES}

Baggen, L.R.; Gurr, G.M.; Meats, A. 1999: Flowers in tri-trophic systems: mechanisms allowing selective exploitation by insect natural enemies for conservation biological control. Entomol. Exp. Appl. 91: 155-161.

Burnip, G.M.; Suckling, D.M. 1997: Evaluation of legumes for development of leafroller-free orchard understories. Proc. 50 $0^{\text {h }}$ Plant Prot Conf:: 420-424.

Charles, J.G.; Walker, J.T.S.; White, V. 1996: Leafroller phenology and parasitism in Hawkes Bay, New Zealand, canefruit gardens. N.Z. J. Crop Hort. Sci. 24: 123-131.

Danthanarayana, W. 1983: Population ecology of the lightbrown apple mothEpiphyas postvittana (Walker) (Lepidoptera:Tortricidae). J. Anim. Ecol. 52:1-33.

Irwin, N.A.; Wratten, S.D.; Chapman, R.B.; Frampton, C.M. 1999: Effects of floral resources on fitness of the leafroller parasitoid (Dolichogenidea tasmanica) in apples. Proc. $52^{\text {nd }}$ N.Z. Plant Prot. Conf.: 84-88.

Lo, P.L.; Suckling, D.M.; Bradley, S.J.; Walker, J.T.S.; Shaw, P.W.; Burnip, G.M. 2000: Factors affecting feeding site preferences of the lightbrown apple moth, Epiphyas postvittana (Lepidoptera: Tortricidae). N.Z. J. Crop Hort. Sci. 28: 235-243.

Singh, P. 1983: A general purpose dietary mixture for rearing insects. Ins. Sci. Applic. 4: 357-362

Suckling, D.M.; Burnip, G.M.; Walker, J.T.S.; Shaw, P.W.; McLaren, G.F.; Howard, C.R.; Lo, P.L.; White, V.; Fraser, J. 1998: Abundance of leafrollers and their parasitoids on selected host plants in New Zealand. N.Z. J. Crop Hort. Sci. 26:193-203.

Suckling, D.M.; Burnip, G.M.; Gibb, A.R.; Daly, J.M.; Armstrong, K.F. 2001: Plant and host effects on the leafroller parasitoid Dolichogenidea tasmanica. Entomol. Exp. Appl. 100: 253-260.

Thomas, W.P.; Burnip, G.M. 1993: Lepidopterous insect pests and beneficials: The influence of understorey. In: McCarthy, T.P.; Daly, D.J.; Burnip, G.M. ed. Proc. Biological Apple Production Seminar. HortResearch, Palmerston North. 78 p.

Van Driesche, R.G.; Bellows Jr, T.S.; Elkinton, J.S; Gould, J.R.; Ferro, D.N. 1991: The meaning of percentage parasitism revisited: solutions to the problem of accurately estimating total losses from parasitism. Environ. Entomol. 20:1-7.

Walker, J.T.S; Wearing, C.H; Rogers, D.J.; Moen, I.C; Immik, E.M.; Colhoun, K., 2002: Leafroller control in organic apple orchards. HortResearch Report No. 2002/246. HortResearch, Palmerston North. 26 p. 